\title{
Production and Characterization of Melanin from Streptomyces Cavourensis Strain RD8 Using Response Surface Optimization
}

\author{
Riddhi Naresh Dholakiya ${ }^{1}$, Madhava Anil Kumar ${ }^{1}$, Kalpana H. Mody ${ }^{1, *}$ \\ ${ }^{1}$ Marine Biotechnology and Ecology Division, CSIR-Central Salt \& Marine Chemicals Research Institute, \\ Bhavnagar (India). \\ Email: kalpanahmody@gmail.com
}

\begin{abstract}
Streptomyces cavourensis strain RD8, a marine actinomycete capable to produce melanin with high antioxidant activity was screened and optimized the production using the chemometric statistical tools. The results from the optimization study revealed that the melanin production could be enhanced when medium is supplemented with L-tyrosine, 0.15, casein, 1.0 and sodium nitrate, 1.0 $(\mathrm{g} / 100 \mathrm{~mL})$ at $\mathrm{pH} 7.0$ and $30^{\circ} \mathrm{C}$ at $120 \mathrm{rpm}$. The purified melanin exhibited potential antibacterial and antioxidant activities. The stability of melanin with respect to antioxidant activity against $\mathrm{pH}$, temperature and salts were also observed. The outcome of the study suggested that $S$. cavourensis strain RD8 would be a potential candidate for melanin production with minimum medium components which could furthermore nurture as natural antioxidants in the food, cosmetic and pharmaceutical industries.
\end{abstract}

Keywords Chemometric; melanin; optimization; Streptomyces cavourensis

\section{Introduction}

Melanin is bioactive-complex pigment which helps to protect the microorganisms from environmental stresses (Sutton and Winterbourn, 1989; Nosanchuk and Casadevall, 2006. They are insoluble in aqueous and organic solvents, thus understanding their fate using conventional biochemical and biophysical techniques are difficult (Abdelfattah, 2013). Pigmented compounds from microbes are provisionally classified as melanin on the basis of their physical and chemical properties (Casadevall et al., 2000). Melanin from microbes has great advantages over animals and plants and generally thought to be environment friendly. The exploration of new novel sources of microbes is drawing attention for the production of new chemical compounds (Suthindhiran and Kannabiran, 2010). Several investigations are presented for the melanin production using actinomycetes for different applications like insecticidal (Liu et al., 1993; Wan et al., 2007), photo-protective creams (Joshua and Arturo, 2003) and pharmaceutical formulations (Sava et al., 2001; Sajiday et al., 2011).

The conventional 'one-factor-at-a-time' (OFAT) method of optimization is laborious, time-consuming and unsuitable for understanding the underlying interactions (Box and Draper, 1987). Due to the economic viability of the melanin production; the optimization of the parameters are a pre-requisite (Guo et al., 2014). The chemometrics are the most promising tools for the proces and product optimization, finding pervasive applications (Karthikeyan et al., 2014; Vidhyadevi et al., 2014; Kumar et al., 2012). The present study describes melanin production from actinomycete isolated from Gulf of Khambhat (GoK) and also focuses on screening of macronutrients and quantifying operational parameters using chemometrics. The research also evaluates the antibacterial and antioxidant activities of the purified melanin against the abiotic stresses.

\section{$2 \quad$ Materials and Methods}

\subsection{Chemicals}

L-tyrosine, L-3,4-dihydroxyphenylalanine (L-DOPA) and standard melanin were obtained from SigmaAldrich, Mumbai. All medium components were obtained from HiMedia, India. All the chemicals were of 
highest purity and analytical grade. The standard melanin was prepared by dissolving the melanin in alkaline distilled water ( $\mathrm{pH} 8.0)$.

\subsection{Isolation and Screening of Melanin Producing Marine Actinomycete}

Marine sediment samples were collected from coastal areas of GoK, near a ship scraping industry $\left(21^{\circ} 24^{\prime} 35.85^{\prime \prime} \mathrm{N}, 72^{\circ} 11^{\prime} 54.1^{\prime \prime} \mathrm{E}\right)$ and after suitable dilution, the samples were inoculated in modified Gause's synthetic agar (GSA) medium containing (g/L): starch, 20; KNO3, 1.0; NaCl, 0.5; K2HPO4, 0.5; $\mathrm{MgSO} 4 \cdot 7 \mathrm{H} 2 \mathrm{O}, 0.5$; FeSO4.7H2O, 0.01; agar, 20 and potassium dichromate, 0.001 was supplemented to inhibit the non-indigenous growth of microorganisms. The primary screening of melanin producing isolates were done by streaking the isolated actinomycetes on tyrosine casein agar medium (TCA) containing (g/L): L-tyrosine, 1.0; casein, 10; sodium nitrate, 10; agar, 25; pH 7.0 and incubated at $30^{\circ} \mathrm{C}$ for $96 \mathrm{~h}$ (Selvakumar et al., 2008). The actinomycetes were screened by observing a diffusible black colored pigment around the colonies on the agar medium. The secondary screening of melanin producing isolates was done by inoculating the selected isolates into TCA medium, incubated at $30^{\circ} \mathrm{C}$ and $120 \mathrm{rpm}$ for 168-192 h. The melanin concentration was quantified by measuring the formation of dopachrome from L-DOPA spectrophotometrically at $300 \mathrm{~nm}$ on Shimadzu UV-1800 spectrophotometer model (Tokyo, Japan). The 16S rRNA gene sequencing was done and the sequences were deposited in the NCBI Gen Bank database (http://www.ncbi.nlm.nih.gov) for obtaining accession number.

\subsection{Response Surface Modeling}

The melanin production was optimized by running the experiments with 20 different experimental combinations of the process parameters given by the central composite design (CCD) matrix. The parametric effects on the dependent response (melanin yield) were modelled using 'Design Expert' (Version 8.0, Stat-Ease Inc., Minneapolis, USA). The range of the independent variables; L-tyrosine (A), casein $(\mathrm{B})$ and sodium nitrate $(\mathrm{C})$ in the $\mathrm{CCD}$ matrix were given by the relation below:

$$
\begin{gathered}
\mathrm{A}=\frac{\mathrm{L}-\text { tyrosine }(g / 100 \mathrm{~m} L)-0.1(\mathrm{~g} / 100 m L)}{0.05(\mathrm{~g} / 100 \mathrm{~mL})} \\
\mathrm{B}=\frac{\operatorname{Casein}(\mathrm{g} / 100 \mathrm{~m} L)-1.0(\mathrm{~g} / 100 \mathrm{~mL})}{0.5(\mathrm{~g} / 100 \mathrm{~mL})} \\
6 \mathrm{C}=\frac{\text { Sodium nitrate }(\mathrm{g} / 100 m L)-1.0(\mathrm{~g} / 100 \mathrm{~mL})}{0.5(\mathrm{~g} / 100 ? \mathrm{~L})}
\end{gathered}
$$

The regression model was developed to test the significance and goodness-of-fit by evaluating the correlation $\left(R^{2}\right)$, predicted $\left(R_{\text {predicted }}^{2}\right)$ and adjusted $\left(R_{\text {adjusted }}^{2}\right)$ coefficients, Student's t-distribution, F-ratio, $\mathrm{P}$-value and analysis of variance (ANOVA). The response surface plots were generated to understand the underlying interactions between the independent parameters.

\subsection{Melanin Purification and Characterization}

The grown culture was centrifuged at $10^{\circ} \mathrm{C}$ and $12,000 \mathrm{rpm}$ for $10 \mathrm{~min}$ and the supernatant was neutralized followed by addition of $1.0 \%$ potassium per-sulphate. The mixture was allowed to stand for $2 \mathrm{~h}$ at room temperature with intermittent shaking. After $2 \mathrm{~h}$, half volume of methanol was added to the total solution and kept for $72 \mathrm{~h}$ at room temperature. The solution was centrifuged and the pellets were dissolved in alkaline distilled water and $\mathrm{pH}$ was adjusted to 3.0. The precipitates were washed with alkaline distilled water and dialyzed followed by lyophilisation (Dong and Yao, 2012). The melanin purification was done using ion exchange chromatography using Sephadex LH-20 column, preequilibrated with $20 \mathrm{mM}$ potassium phosphate buffer ( $\mathrm{pH}$ 7.0). The bound melanin was eluted by buffer at a flow rate of $20 \mathrm{~mL} / \mathrm{h}$ and fractions $(2 \mathrm{~mL})$ were assayed for the presence of melanin. The melanin rich fractions were pooled, dialyzed and freeze-dried. The melanin was characterized using UV-Vis spectrophotometric, Fourier transform infrared (FT-IR) spectroscopic and elemental (CHNS) analyses. 
UV-Vis absorption spectrum of melanin was scanned in the region between 200-400 nm. The functional moieties of melanin were compared with the standard melanin using FT-IR spectrometer in the range 4000-400 $\mathrm{cm}^{-1}$ using GX-FT-IR system, Perkin Elmer, USA. CHNS analyses were carried out using ElementerVario Micro Cube, Germany.

\subsection{Antioxidant Activity Assays}

The antioxidant activity of the purified melanin was assessed by measuring the ability of melanin to scavenge 2, 2-diphenyl-1-picrylhydrazyl (DPPH) and hydrogen peroxide $\left(\mathrm{H}_{2} \mathrm{O}_{2}\right)$ radicals spectrophotometrically at 517 and $230 \mathrm{~nm}$ (Bersuder et al., 1998; Keser et al., 2014). Fe ${ }^{2+}$ chelating activity of melanin was determined by measuring the percentage inhibition of ferrozine-Fe ${ }^{2+} \mathrm{complex}$ formation at $562 \mathrm{~nm}$ (Dinis et al., 1994). The control sets were always included which contained all the components except melanin. All the experiments were performed in triplicates and the percentage radical scavenging and chelating activities were quantified using the relation;

$$
\begin{gathered}
\text { Radicalscavengingactivity }(\%)=\frac{\text { Control }_{\text {Absorbance }}-\text { Sample }_{\text {Absorbance }}}{\text { Control }_{\text {Absorbance }}} \times 100 \\
F e^{2+} \text { chelating }(\%)=\frac{\text { Control }_{\text {Absorbance }}-\text { Sample }_{\text {Absorbance }}}{\text { Control }_{\text {Absorbance }}} \times 100
\end{gathered}
$$

\subsection{Stability and Antibacterial Activity Analyses}

The stability analyses of melanin with respect to antioxidant activities were tested by incubating 0.04 $\mathrm{mg} / \mathrm{mL}$ melanin with the varying levels of $\mathrm{pH}(7.5-12.5)$, temperature $\left(30-70{ }^{\circ} \mathrm{C}\right)$ and $\mathrm{NaCl}(5.0-20 \%)$ at defined time period of incubation and the blank solutions were always included. The antibacterial activity of the standard and purified melanin $(100 \mathrm{\mu g})$ was evaluated using cup plate assay against six Gram negative and two Gram positive bacteria. The antibacterial activity was quantified by measuring the zone of inhibition $(\mathrm{mm})$ around the well and the experiments were performed in triplicates.

\section{$3 \quad$ Results and Discussion}

\subsection{Isolation of Actinomycetes}

GoK is an exclusive niche which nurtures diverse microorganisms with unique properties that can survive under stress conditions (Yousuf et al., 2012). Many reports are available on the marine actinomycetes isolated from the west coast of India, however, according to our knowledge; this is the first investigation reporting on the melanin production from actinomycetes isolated from GoK. 72 isolates of actinomycetes were obtained on GSA medium, out of them five isolates were screened as exhibited the ability to produce melanin with bioactivities. One isolate was selected for further study as producing maximum yield and was identified as Streptomyces cavourensis strain RD8 on the basis of 16SrRNAgene sequencing (accession number KT588658). The phylogenetic relationship of the strain was compared with other species of the genus Streptomyces.

\subsection{Time Course of Melanin Production}

The time required for the melanin production by $S$. cavourensis strain RD8 was studied for a span of $216 \mathrm{~h}$ and maximum melanin yield $(87 \mu \mathrm{g} / \mathrm{mL})$ was observed at $168 \mathrm{~h}$. The melanin production was observed within $24 \mathrm{~h}$ inception of growth as it was an extracellular pigment which increased during the exponential growth phase and reached the maximum at the beginning of the stationary phase (168 h) as shown in Fig.1. The findings from the present study were supported by Manivasagan et al. (2013) under optimized conditions. 


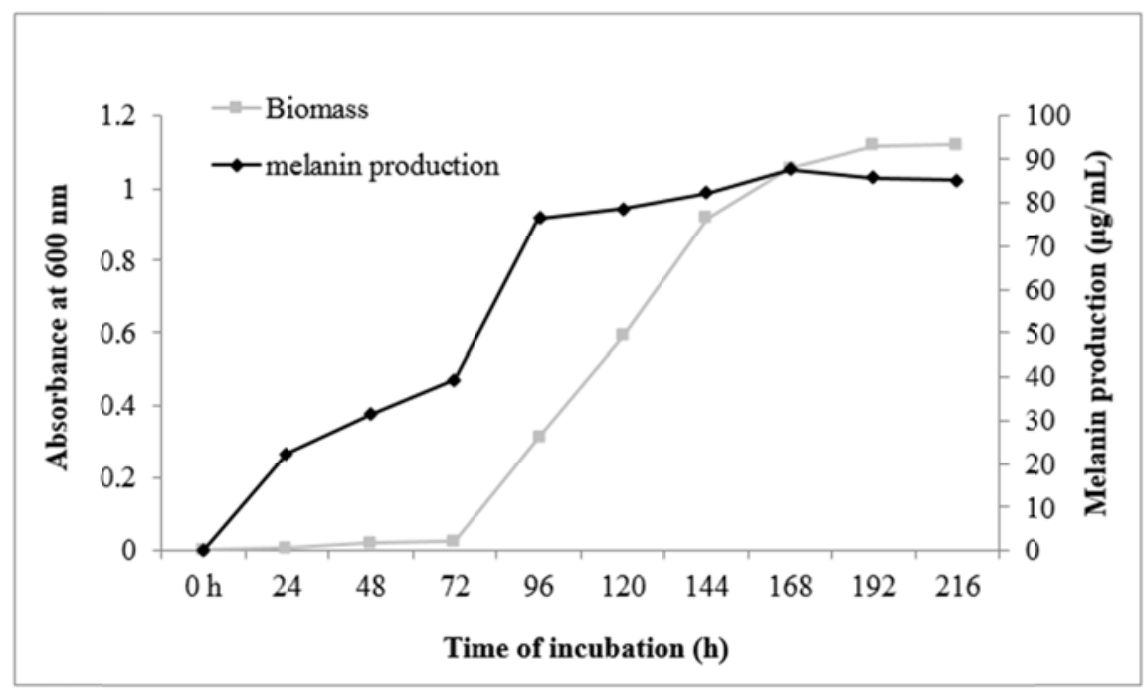

Figure 1. Time profile of melanin production with simultaneous growth of S. cavourensis strain RD 8
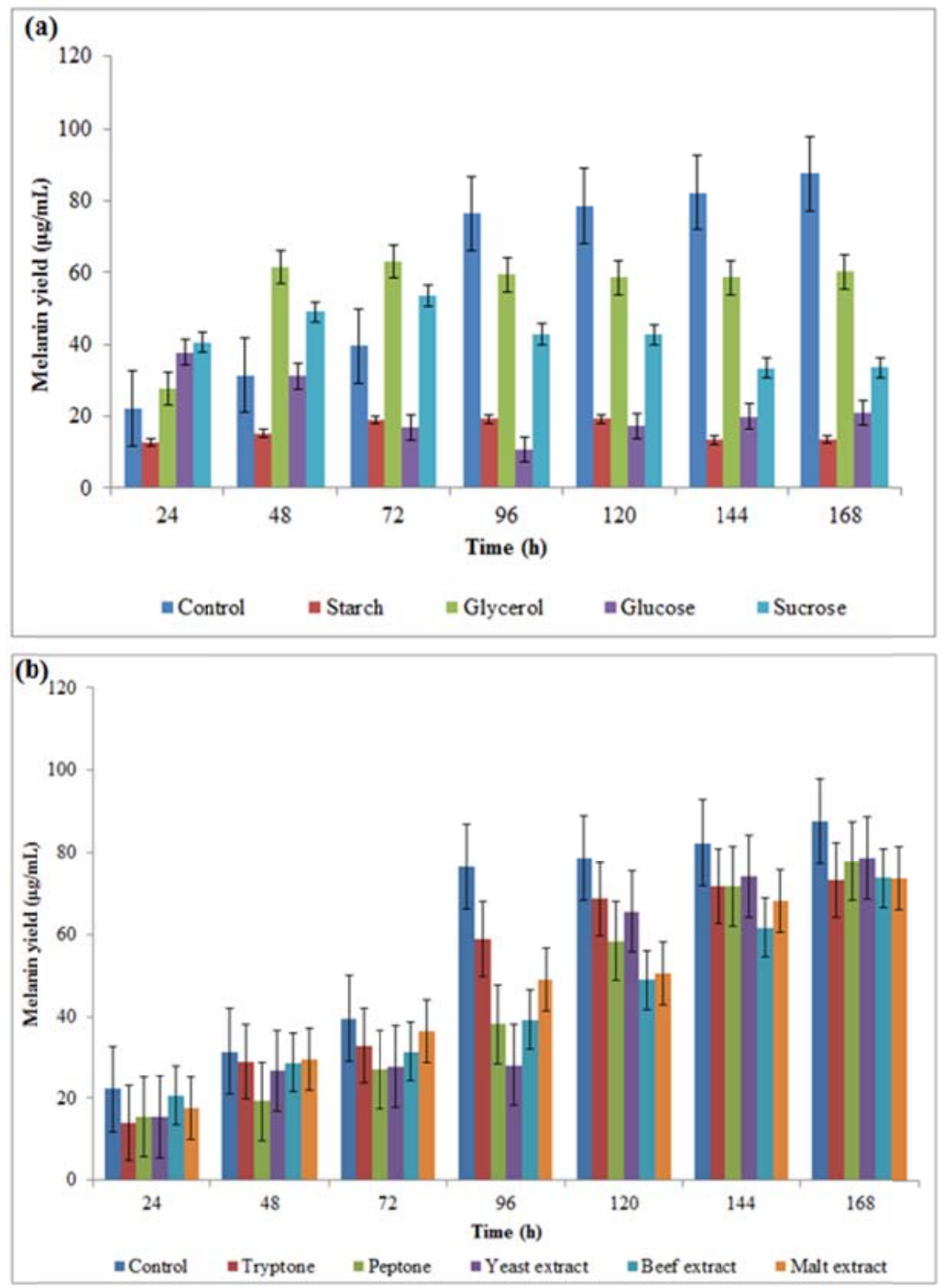

Figure 2. Effect of (a) carbon and (b) nitrogen sources on melanin production by S. cavourensis strain RD8 


\subsection{OFAT Method for Selection of Medium Components}

The melanin production was carried out in a medium containing (g/L): L-tyrosine, 1.0; casein, 10.0 and sodium nitrate, 10.0. The effect of various carbon and nitrogen sources on melanin yield is demonstrated as shown in Fig. 2 (a\&b).L-tyrosine and casein supported as carbon and nitrogen sources for the growth and production. There was an inhibitory effect on the melanin production when the medium wassupplemented with additional carbon sources(starch, glucose, glycerol and sucrose). Several researchers found that the different species of Streptomyces utilized L-tyrosine for the melanin production (Surwase et al., 2013; Guo et al., 2014; Kiran et al., 2014).

Similarly, sodium nitrate was proved as a salt of choice in the medium, because few experiments were performed by replacing sodium nitrate by different salts (sodium chloride, sodium sulphate and sodium carbonate) to monitor the effect on melanin production. It was observed that during the initial phase of growth, the melanin production was supported by sodium sulphate upto $72 \mathrm{~h}$ while, sodium nitrate supported at a later phase. As such, the effects of other salts were almost same on the melanin production.

\subsection{Effect of $\mathrm{pH}$ and Temperature on Melanin Production}

The effect of $\mathrm{pH}(3.0-10.0)$ and temperature $\left(15-40^{\circ} \mathrm{C}\right)$ on the growth and melanin production by $S$. cavourensis strain RD8 for a span of $168 \mathrm{~h}$ was studied (Fig.3a\&b). The melanin production was high when the $\mathrm{pH}$ was 4.0-7.0 and the melanin concentration increased from 37 to $82.6(\mu \mathrm{g} / \mathrm{mL})$ when the time was increased from 24 to $168 \mathrm{~h}$.
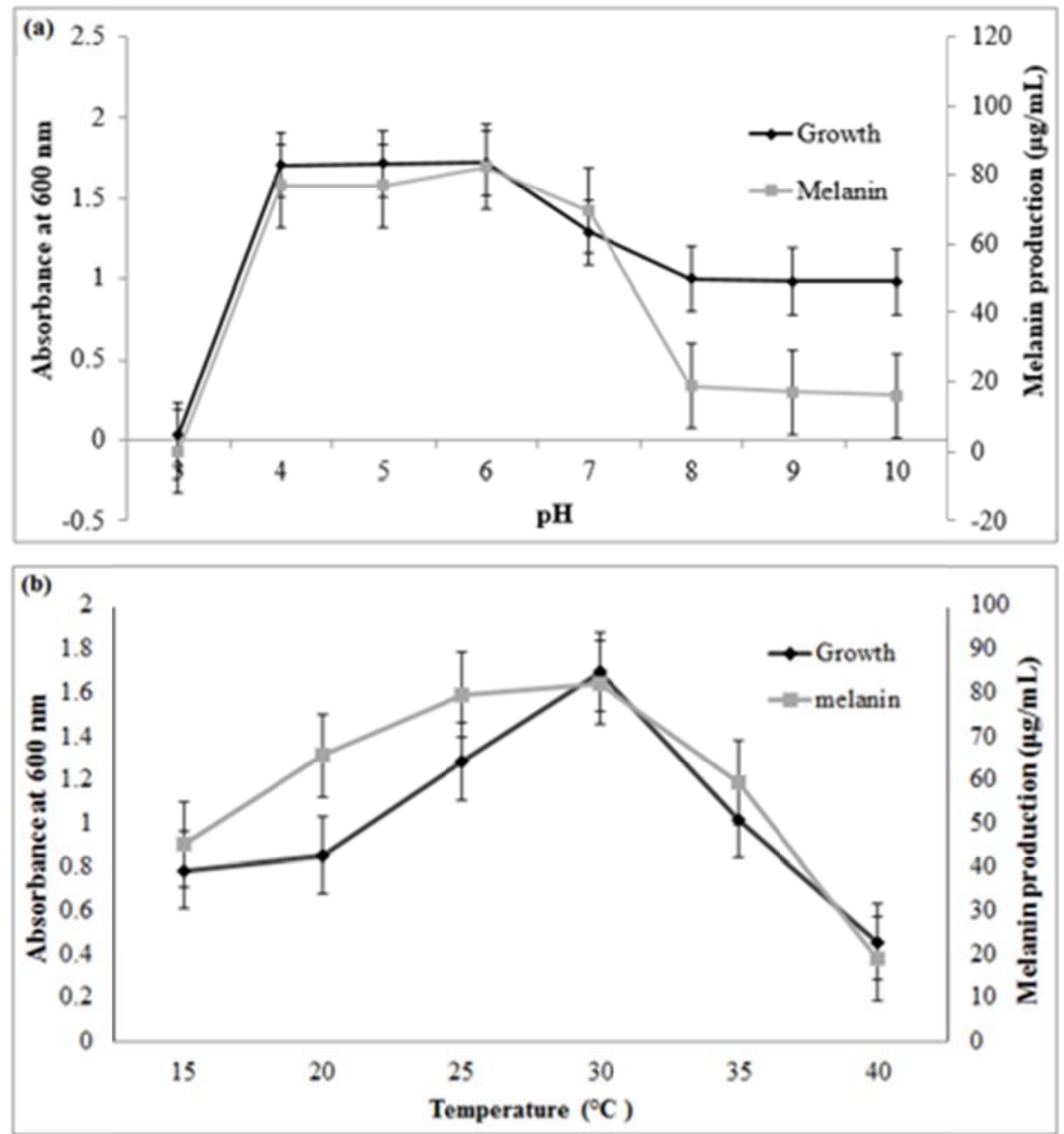

Figure 3. Effect of (a) pH and (b) temperature on growth and melanin production by S. cavourensis strain RD 8 
The melanin production increased with temperature from 15 to $30^{\circ} \mathrm{C}$ after which there was a decrease in the production level. The higher temperature level did not favour the growth of the strain and thus, there was a decrease in the production. The melanin production was $45 \mu \mathrm{g} / \mathrm{mL}$ at $15^{\circ} \mathrm{C}$ which increased with $82 \mathrm{\mu g} / \mathrm{mL}$ at $30^{\circ} \mathrm{C}$, while 59 and $19 \mathrm{\mu g} / \mathrm{mL}$ was observed at 35 and $40^{\circ} \mathrm{C}$ respectively. It can be concluded that $30^{\circ} \mathrm{C}$ was optimum temperature for the growth of the strain as well as for the melanin production.

\subsection{Regression Model Analysis}

The melanin yield for the different experimental combinations given by the central composite design (CCD) matrix was found in the range of 11.09-115.99 $(\mathrm{\mu g} / \mathrm{mL})$. The highest and lowest yields were observed after $168 \mathrm{~h}$ of incubation with $S$. cavourensis strain RD 8 in the run \#10 and \#7 respectively as shown in Table 1.

Table 1. The observed response for the CCD matrix

\begin{tabular}{c|c|c|c|c}
\hline $\begin{array}{c}\mathbf{R u} \\
\mathbf{n}\end{array}$ & $\begin{array}{c}\text { L-tyrosine }(\mathrm{g} / \mathbf{1 0 0} \\
\mathbf{m L})\end{array}$ & $\begin{array}{c}\text { Casein }(\mathrm{g} / \mathbf{1 0 0} \\
\mathbf{m L})\end{array}$ & $\begin{array}{c}\text { Sodium nitrate }(\mathrm{g} / \mathbf{1 0 0} \\
\mathbf{m L})\end{array}$ & $\begin{array}{c}\text { Melanin yield } \\
(\mathbf{\mu g} / \mathbf{m L})\end{array}$ \\
\hline 1 & 0.05 & 0.5 & 0.5 & 27.51 \\
\hline 2 & 0.15 & 0.5 & 0.5 & 25.55 \\
\hline 3 & 0.05 & 1.5 & 0.5 & 48.03 \\
\hline 4 & 0.15 & 1.5 & 0.5 & 91.30 \\
\hline 5 & 0.05 & 0.5 & 1.5 & 12.90 \\
\hline 6 & 0.15 & 0.5 & 1.5 & 22.79 \\
\hline 7 & 0.05 & 1.5 & 1.5 & 62.52 \\
\hline 8 & 0.15 & 1.5 & 1.5 & 76.40 \\
\hline 9 & 0.05 & 1.0 & 1.0 & 115.99 \\
\hline 10 & 0.15 & 1.0 & 1.0 & 25.96 \\
\hline 11 & 0.1 & 0.5 & 1.0 & 60.37 \\
\hline 12 & 0.1 & 1.5 & 1.0 & 63.31 \\
\hline 13 & 0.1 & 1.0 & 0.5 & 47.69 \\
\hline 14 & 0.1 & 1.0 & 1.5 & 87.62 \\
\hline 15 & 0.1 & 1.0 & 1.0 & 87.62 \\
\hline 16 & 0.1 & 1.0 & 1.0 & 87.62 \\
\hline 17 & 0.1 & 1.0 & 1.0 & 87.62 \\
\hline 18 & 0.1 & 1.0 & 1.0 & 87.62 \\
\hline 19 & 0.1 & 1.0 & 1.0 & 87.62 \\
\hline 20 & 0.1 & 1.0 & 1.0 & \\
\hline
\end{tabular}

The optimal levels of the operational parameters were predicted by fitting the responses in a regression model as follows;

$$
\begin{aligned}
& \text { Melanin yield }(\mu \mathrm{g} / \mathrm{mL})=84.99+14.22 \mathrm{~A}+15.86-9.87 C+10.85 A B \\
& +2.5 A C-6.04 \mathrm{C}+15.15^{2}-37.88 B^{2}-25.54 C^{2}
\end{aligned}
$$

The adequacy of the model was tested by ANOVA as shown in Table 2, the model had low P-value $(<0.0001)$ and high F-value $(86.23) . R^{2}, R_{\text {predicted }}^{2}$ and $R_{\text {adjusted }}^{2}$ were $0.987,0.927$ and 0.976 respectively, indicating that the operational parameters contributed positively in enhancing the response and also estimated the significance and goodness-of-fit of developed model (Box and Behnken, 1960; Montgomery et al., 1992; Khuri and Cornell, 1996). The fitted model had greater adequacy and reliability which is explained by the coefficient of variation (CV), 8.0\%. Additionally, the model adequacy was evaluated in terms of normal probability, perturbation and response surface plots (Cook and Weisberg, 1982; Khataee et al., 2011; Kumar et al., 2015). 
Table 2. ANOVA for melanin yield $(\mu \mathrm{g} / \mathrm{mL})$

\begin{tabular}{l|c|c|c|c|c}
\hline Source & Sum of squares & Degrees of freedom & Mean squares & F-value & P-value (Prob $>$ F $)$ \\
\hline Model & 18417.30 & 9 & 2046.37 & 86.23 & $<0.0001$ \\
\hline$A$ & 2022.65 & 1 & 2022.65 & 85.23 & $<0.0001$ \\
\hline$B$ & 2515.40 & 1 & 2515.40 & 106.00 & $<0.0001$ \\
\hline$C$ & 974.37 & 1 & 974.37 & 41.06 & $<0.0001$ \\
\hline$A^{2}$ & 631.49 & 1 & 631.49 & 26.61 & $<0.0001$ \\
\hline$B^{2}$ & 3945.20 & 1 & 3945.20 & 166.25 & 0.1771 \\
\hline$C^{2}$ & 1793.99 & 1 & 1793.99 & 75.60 & 0.0056 \\
\hline$A B$ & 941.13 & 1 & 941.13 & 39.66 & 0.0004 \\
\hline$A C$ & 50.05 & 1 & 50.05 & 2.11 & $<0.0001$ \\
\hline$B C$ & 292.22 & 1 & 2922.22 & 12.31 & $<0.0001$ \\
\hline Residual & 237.31 & 10 & 23.73 & & \\
\hline Lack-of-Fit & 237.31 & 5 & 47.46 & & \\
\hline Pure error & 0.000 & 5 & 0.000 & & \\
\hline Correlation Total & 18654.61 & 19 & & & \\
\hline$R^{2}=0.9873$ & & & $R_{\text {predicted }}=0.9273$ & & \\
\hline$R_{\text {adjusted }=0.9758}$ & & CV=8.00\% & & \\
\hline Standard deviation $=4.87$ & & & & \\
\hline
\end{tabular}
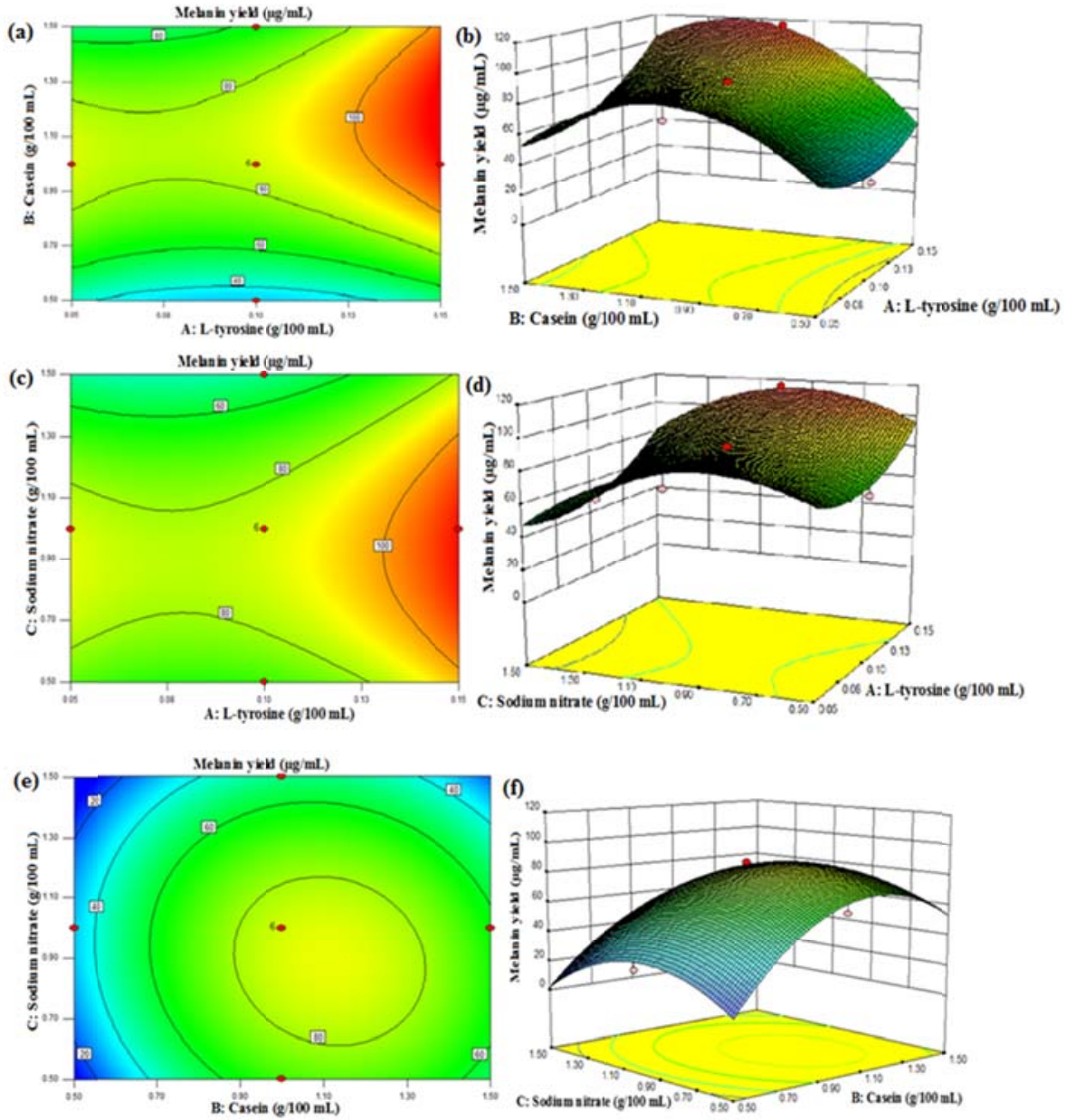

Figure 4. Response surface and contour plots illustrating the effect of L-tyrosine, casein and sodium nitrate on melanin yield $(\mu \mathrm{g} / \mathrm{mL})$ 
The experimental data explained that the responses were highly dependent on the levels of L-tyrosine, casein and sodium nitrate. The interactions among the independent parameters depicted as a spherical and nearly spherical shape which described that the interrelationship has resulted in the maximal response.

\subsection{Melanin Characterization}

CHNS composition of the purified melanin was compared with the standard and crude melanin as shown in the Table 3. The elemental composition of the purified product followed the same trend with the standard and crude melanin and decreased.

Table 3. Comparison of CHNS composition of standard melanin with crude and purified melanin from S. cavourensis strain RD8

\begin{tabular}{l|l|l|l|l}
\hline \multirow{2}{*}{ Melanin } & \multicolumn{4}{|l}{ Weight (\%) } \\
\cline { 2 - 5 } & $\mathbf{C}$ & $\mathbf{H}$ & $\mathbf{N}$ & S \\
\hline Standard & 52.46 & 6.048 & 13.28 & 0.72 \\
\hline Crude & 46.76 & 7.08 & 12.97 & 0.84 \\
\hline Purified & 36.59 & 5.945 & 9.52 & 0.62 \\
\hline
\end{tabular}

$\mathrm{C}$ content was comparatively higher $52.46,46.76$ and 36.59 than $\mathrm{S}$ content $(0.72,0.84$ and 0.62$)$ in the standard, crude and purified melanin respectively. The purified melanin absorbed strongly in the UV region at $310 \mathrm{~nm}$ and progressively decreased with increase in wavelength. This is attributed due to the presence of many complex conjugated structures in the melanin. The functional groups present in the standard, crude and purified melanin were compared as shown in the Fig.5.

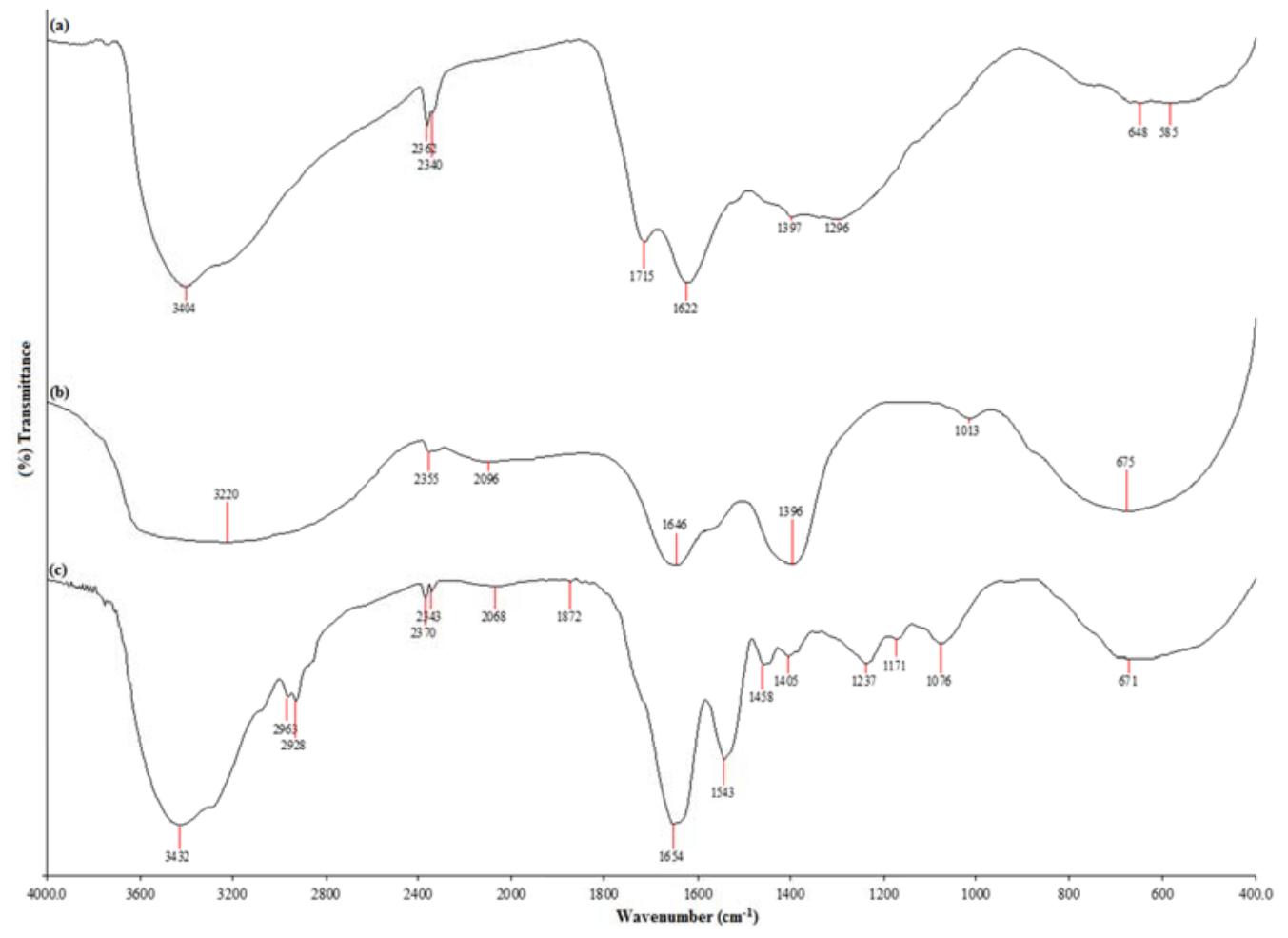

Figure 5. FT-IR spectra (a) standard (b) crude and (c) purified melanin

The spectrum exhibited a broad absorption band at $3346 \mathrm{~cm}^{-1}$ which revealed the presence of $\mathrm{OH}$ stretching of the hydroxyl group supported by peak near $3352 \mathrm{~cm}^{-1}$. The bands at 1029 and $1112 \mathrm{~cm}^{-1}$ 
were assigned to $\mathrm{CN}$ stretch related to aliphatic amines (Suryanarayanan et al., 2004) and $1654 \mathrm{~cm}^{-}$ ${ }^{1}$ refers to the $\mathrm{NH}$ stretching of the amino group. The peak at $2943 \mathrm{~cm}^{-1}$ was attributed to $\mathrm{CH}$ stretching of alkanes. The band at $1446 \mathrm{~cm}^{-1}$ describes $\mathrm{CC}$ stretch of the aromatic group and the comparative spectra proved that the product was melanin.

\subsection{Antioxidant and Antibacterial Activities of Melanin}

The antioxidant activities of melanin against abiotic stresses like $\mathrm{pH}(7.5-12.5)$, temperature $\left(30-70^{\circ} \mathrm{C}\right)$ and sodium chloride (5-20\%) were evaluated as shown in Fig.6. The purified mellanin exhibited 28.01, 86.97 and $81.31 \%$ at $\mathrm{pH} 8.0$, while the activities were $61.91,84.0$ and $98.4 \%$ of $\mathrm{DPPH}, \mathrm{H}_{2} \mathrm{O}_{2}$ scavenging and $\mathrm{Fe}^{2+}$ chelating activities respectively at $50^{\circ} \mathrm{C}$. The results were in correlation with the standard (Goncalves and Pombeiro-Sponchiado, 2005). Similarly, 5\% (w/v) NaCl exhibited maximal activities and decreased with furthermore increase in salt concentration.



Figure 6. Radical scavenging and metal chelating activities of purified melanin with respect to $\mathrm{pH}$, temperature and salt concentration

The antimicrobial activity of the purified melanin were assayed by the agar well diffusion method against eight different pathogenic bacteria and compared with the standard melanin as shown in Table 4 .

The purified melanin showed maximum antibacterial activity against Escherichia coli and Salmonella entertidi while lowest activity against Shigella boydii. The standard melanin was more active against $E$. coli, E. cloacae, Klebsiella pneumoniae and Salmonella entertidi than purified melanin. Pseudomonas spp. was only sensitive against standard melanin. 
Table 4. Antibacterial test of melanin $(100 \mu \mathrm{g} / \mathrm{mL})$

\begin{tabular}{c|l|c|c}
\hline \multirow{2}{*}{ No. } & \multirow{2}{*}{ Bacteria } & \multicolumn{2}{|c}{ Zone of clearance (mm) } \\
\cline { 3 - 4 } & & Standard melanin & Purified melanin \\
\hline 1 & Escherichia coli & $27 \pm 0.58$ & $25 \pm 0.58$ \\
\hline 2 & Staphylococcus spp. & $14 \pm 0.58$ & $14 \pm 0.58$ \\
\hline 3 & Shigella boydii & $17 \pm 0.58$ & $13 \pm 0.58$ \\
\hline 4 & Enterobacter cloacae & $25 \pm 0.58$ & $22 \pm 0.58$ \\
\hline 5 & Klebsiella pneumoniae & $25 \pm 1.0$ & $23 \pm 1.0$ \\
\hline 6 & Pseudomonas spp. & $20 \pm 0.58$ & $\mathrm{ND}$ \\
\hline 7 & Salmonella entertidi & $27 \pm 0.58$ & $25 \pm 0.58$ \\
\hline 8 & Bacillus pumilus & $18 \pm 0.58$ & $14 \pm 0.58$ \\
\hline
\end{tabular}

ND-Not Detected

\section{Conclusions}

Streptomyces cavourensis strain RD8, from GoK possessed the ability to produce melanin with greater antioxidant and antibacterial activities. This study also suggested that $S$. cavourensis strain RD8 could be a potential candidate for the melanin production which could be used as the natural antioxidant in the cosmetics, food and pharmaceutical industries.

Acknowledgement. The authors are grateful to the Director, CSIR-CSMCRI, Bhavnagar, for the support extended. We are grateful to AD \& CIF of CSIR-CSMCRI for the analytical techniques. This is CSIR-CSMCRI contribution No. 015/2016.

\section{References}

1. M.S. Abdelfattah, "A new bioactive aminophenoxazinone alkaloid from a marine-derived actinomycetes,"Natural Product Research, vol. 27, pp. 2126-2131, 2013.

2. P. Bersuder, M. Hole and G. Smith, "Antioxidants from a heated histidine-glucose model system. I: Investigation of the antioxidant role of histidine and isolation of antioxidants by high-performance liquid chromatography,"Journal of American Oil Chemist's Society, vol. 75, pp. 181-187, 1998.

3. G.E.P. Box and D.W. Behnken,"Some new three level designs for the study of quantitative variables,"Technometrics, vol. 2, pp. 455-475, 1960.

4. G.E.P. Box and N.R. Draper,"Empirical model-building and response surfaces," Wiley, New York, 1987.

5. A. Casadevall, A.L. Rosasand, J.D. Nosanchuk, "Melanin and virulence in Cryptococcus neoformans,"Current Opinion in Microbiology, vol. 3,pp. 354-358, 2000.

6. R.D. Cook and S. Weisberg, "Residuals and Influence in Regression," London \& New York, Chapman \& Hall, 1982.

7. T.C.P Dinis, V.M.C Madeira and L.M. Almeida,"The action of phenolic derivatives (acetaminophen, salicylate, and 5- aminosalicylate) as inhibitors of membrane lipid peroxidation and as peroxyl radical scavengers,"Archives of Biochemistry and Biophysics, vol. 315, pp. 161-169, 1994.

8. C. Dong and Y. Yao, "Isolation, characterization of melanin derived from Ophiocordycepssinensis, an entomogenous fungus endemic to the Tibetan Plateau,"Journal of Bioscience and Bioengineering, vol. 113, pp. 474-479, 2012.

9. R.C.R. Goncalves and S.R. Pombeiro-Sponchiado, "Antioxidant activity of the melanin pigment extracted from Aspergillus nidulans,"Biological \& Pharmaceutical Bulletin, vol. 28, pp. 1129-1131, 2005.

10.J. Guo, Z. Rao, T. Yang, Z. Man, M. Xuand X. Zhang,"High-level production of melanin by a novel isolate of Streptomyces kathirae,"FEMS Microbiology Letters, vol. 357, pp. 85-91, 2014.

11.D.N. Joshua and C. Arturo, "The contribution of melanin to microbial pathogenesis", Cellular Microbiology, vol. 5, pp. 203-223, 2003.

12.S. Karthikeyan, M.A. Kumar, P. Maharaja, B.P. Rao and G. Sekaran, "Process optimization for the treatment of 
pharmaceutical wastewater catalyzed by a poly sulpha sponge,"Journal of the Taiwan Institute of Chemical Engineers, vol. 45, pp. 1739-1747, 2014.

13.S. Keser, S. Celik, S. Turkoglu, Ö. Yilmaz and I. Turkoglu, "The investigation of some bioactive compounds and antioxidant properties of hawthorn (Crataegusmonogyna subsp. monogynaJacq), "Journal of InterculturalEthnopharmacology, vol. 3, pp. 51-55, 2014.

14.A.R. Khataee, M. Zarei, M. Fathinia and M.K. Jafari,"Photocatalytic degradation of an anthraquinone dye on immobilized TiO2 nanoparticles in a rectangular reactor: Destruction pathway and response surface approach,"Desalination, vol. 268, pp. 126-133, 2011.

15.A. I. Khuriand J. A. Cornell,"Response Surfaces," 2nd edition. New York, Dekker, 1996.

16.G.S. Kiran, A. Dhasayan, A.N. Lipton, J. Selvin, M.V. Arasu and N.A. Al-Dhabi,"Melanin-templated rapid synthesis of silver nanostructures",Journal of Nanobiotechnology, vol. 12, pp. 18, 2014.

17.M.A. Kumar, V.V. Kumar, M.P. Premkumar, P. Baskaralingam, K.V. Thiruvengadaravi, D. Anuradha and S. Sivanesan, "Chemometric formulation of bacterial consortium-AVS for improved decolorization of resonancestabilized and heteropolyaromatic dyes,"Bioresource Technology, vol.123, pp. 344-351, 2012.

18.Y.T. Liu, M.J. Sui, D.D. Ji, I.H. Wu, C.C. Chou and C.C. Chen,"Protection from ultraviolet irradiation by melanin of mosquitocidal activity of Bacillus thuringiensis var. Israeliensis,"Journal of Invertebrates Pathology, vol. 62, pp. 131-136, 1993.

19.P. Manivasagan, J. Venkatesan, K. Sivakumar and S. Kim, "Marine actinobacterial metabolites: Current status and future perspectives,"Microbiological Research, vol. 168, pp. 311-332, 2013.

20.D.C. Montgomery, G.G. Vining and E.A. Peck, "Introduction to linear regression analysis," New York, John and Wiley and Sons, Inc., 1992.

21.P. Selvakumar, S. Rajasekar, K. Periasamy and N. Raaman, "Isolation and characterization of melanin pigment from Pleurotuscystidiosus (telomorph of Antromycopsismacrocarpa),"World Journal of Microbiology and Biotechnology, vol.24, pp. 2125-2131, 2008.

22.S.N. Surwase, S.B. Jadhav, S.S. Phugare and J.P. Jadhav, "Optimization of melanin production by Brevundimonas sp. SGJ using response surface methodology,"3Biotech, vol. 3, pp. 187-194, 2013.

23.T.S. Suryanarayanan, J.P. Ravishankar, G. Venkatesan and T.S. Murali, "Characterization of the melanin pigment of a cosmopolitan fungal endophyte,"Mycology Research, vol. 108, pp. 974-978, 2004.

24.K. Suthindhiran and K. Kannabiran, "Diversity and exploration of bioactive marine actinomycetes in the Bay of Bengal of the Puducherry coast of India,"Indian Journal of Microbiology, vol. 50,pp. 76-82, 2010.

25.J.D. Nosanchuk and A. Casadevall, "Impact of melanin on microbial virulence and clinical resistance to antimicrobial compounds,"Antimicrobial Agents in Chemotherapy, vol. 50, pp. 3519-3528, 2006.

26.H. Sutton and C. Winterbourn,"On the participation of higher oxidation states of iron and copper in Fenton reactions,"Free Radical Biology and Medicine,vol. 6,pp. 53-60, 1989.

27.T. Vidhyadevi, A. Murugesan, S.S. Kalaivani, M.A. Kumar, K.V.T. Ravi, L. Ravikumar, C.D. Anuradha and S. Sivanesan, "Optimization of the process parameters for the removal of reactive yellow dye by the low cost Setariaverticillata carbon using response surface methodology: Thermodynamic, kinetic and equilibrium studies," Environmental Progressand Sustainable Energy, vol. 33, pp. 855-865, 2014.

28.X. Wan, H.M. Liu, Y. Liao, Y. Su, J. Geng, M.Y. Yang, X.D. Chen and P. Shen, "Isolation of a novel strain of Aeromonas media producing high levels of DOPA-melanin and assessment of the photoprotective role of the melanin in bioinsecticide applications,"Journal of Applied Microbiology, vol. 103, pp. 2533-2541, 2007.

29.M.A. Kumar, V.V. Kumar, R. Ponnusamy, F.P. Daniel, M. Seenuvasan, C.D. Anuradha and S. Sivanesan, "Concomitant mineralization and detoxification of acid red 88 by an indigenous acclimated mixed culture,"Environmental Progress and Sustainable Energy, vol.34, pp. 1455-1466, 2015.

30.I. Sajiday, K.A. Shaaban and S. Hasnain, "Antitumour compounds from a saline soil isolate, Streptomyces griseoincarnatus CTF15,"Natural Product Research, vol. 25, pp. 549-559,2011.

31.V.M. Sava, B.N. Oalkin, M.Y. Hong, P.C. Yang and G.S. Huang, "A novel melanin-like pigment derived from black tea leaves with immuno-stimulating activity," Food Research International, vol. 34, pp. 337-343, 2001.

32.B. Yousuf, P. Sanadhya, J. Keshri and B. Jha, "Comparative molecular analysis of chemolithoautitrophic bacterial diversity and community structure from coastal saline soils, Gujarat, India," BMC Microbiology, vol. 12: pp. 150, 2012. 